Article

\title{
Design and Investigation of Modern UWB-MIMO Antenna with Optimized Isolation
}

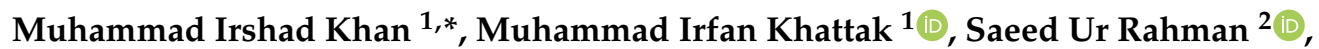 \\ Abdul Baseer Qazi ${ }^{3} \mathbb{D}$, Ahmad Abdeltawab Telba ${ }^{4}$ and Abdelrazik Sebak ${ }^{5}$ \\ 1 Department of Electrical Engineering, University of Engineering and Technology, Peshawar 25000, Pakistan; \\ M.I.Khattak@uetpeshawar.edu.pk \\ 2 College of Electronic and Information Engineering, Nanjing University of Aeronautics and \\ Astronautics (NUAA), Nanjing 210016, China; saeed@nuaa.edu.cn \\ 3 Department of Software Engineering, Bahria University, Islamabad 44000, Pakistan; abq.buic@bahria.edu.pk \\ 4 Department of Electrical Engineering, King Saud University, Riyadh 11421, Saudi Arabia; atelba@ksu.edu.sa \\ 5 Electrical and Computer Engineering, Concordia University, Montreal, QC H3G 1M8, Canada; \\ abdo@ece.concordia.ca \\ * Correspondence: m.i.khan@uetpeshawar.edu.pk
}

Received: 27 March 2020; Accepted: 15 April 2020; Published: 20 April 2020

\begin{abstract}
This paper proposes a compact, semi-circular shaped multiple input multiple output (MIMO) antenna design with high isolation and enhanced bandwidth for ultrawide band (UWB) applications. A decoupling stub is used for high isolation reaching up to $-55 \mathrm{~dB}$ over the entire bandwidth. The proposed antenna is used for UWB as well as super wide band (SWB) applications. The overall size of the proposed antenna is $18 \times 36 \times 1.6 \mathrm{~mm}^{3}$. The $\left|S_{11}\right|$ and voltage standing wave ratio (VSWR) of the proposed antenna are less than $-10 \mathrm{~dB}$ and 2, respectively, in the range of 3-40 GHz. The total impedance bandwidth of the proposed design is $37 \mathrm{GHz}$. The VSWR, $\left|S_{11}\right|$, $\left|S_{22}\right|,\left|S_{21}\right|,\left|S_{12}\right|$, gain, envelope correlation coefficient (ECC), radiation pattern, and various other characteristic parameters are discussed in detail. The proposed antenna is optimized and simulated in a computer simulation technology (CST) studio, and printed on a FR4 substrate.
\end{abstract}

Keywords: Ultrawide band; super wide band; multiple input multiple output; voltage standing wave ratio; $\mathrm{S}_{11}$; impedance bandwidth; envelope correlation coefficient; gain

\section{Introduction}

Over the past few decades, the field of antennas for wireless communication systems has been transitioning towards having a single radiator for multiple applications, particularly when the need for higher speeds is in demand by consumers [1]. UWB and super wide band (SWB) antennas are examples of such antennas, and have been research considerations for the reasons stated above [2-7]. These antennas have various advantages, such as fabrication simplicity, low power consumptions, high transmission rate, and low cost [8]. Despite these benefits, SWB antennas also have some limitations, such as multi path fading and channel capacity, which affect the overall performance of such systems [9]. Recently, MIMO structures with multiple radiating elements have been introduced to combat such problems without using more bandwidth and transmitting power [10]. Commonly, MIMO antennas are used on both sides of communication systems (i.e., transmitter and receiver sides), to enhance communication quality and capacity of a channel [11]. Due to deployment of multiple radiating elements in close proximity, MIMO antenna systems adopt mutual coupling, and one of the solutions is to place radiating elements at great distances, which will increase antenna sizes. Tackling these two main challenges are the main focus of a great deal of the current research. For instance, in MIMO antennas, various techniques have been used to minimize mutual couplings [12-30]. 
Keeping the above challenges in mind, the intent of this research was to design and analyze a planar MIMO antenna, which smaller in size, with a reduced mutual coupling between the radiating elements while maintaining a high degree of performance in terms of bandwidth, gain and efficiency with a simple design structure. Considered a challenging task, mutual coupling of the radiators in MIMO communications is reduced by introducing a novel T-shaped decoupling stub over the entire bandwidth while maintaining the optimized values of ECC $<0.01$ and diversity gain $(\mathrm{DG})>9.98 \mathrm{~dB}$, and comparable values of gain and efficiency with a simple design structure.

\section{Related Literature}

In rectangular-shaped MIMO antennas, isolation is increased with the help of a narrow slot that is introduced on the ground plane. The size of the antenna is $45 \mathrm{~mm} \times 37 \mathrm{~mm}$ with a $\left|S_{11}\right|$ less than $-10 \mathrm{~dB}$, from 3.1 to $5 \mathrm{GHz}$, which presents an impedance bandwidth of $1.9 \mathrm{GHz}$, isolation of less $-20 \mathrm{~dB}$, and average gain greater than $-2 \mathrm{~dB}$ [1]. In [12], a circular-shaped MIMO antenna was studied with the overall size of $40 \mathrm{~mm} \times 68 \mathrm{~mm}$. An inverted Y-shaped stub was used to enhance the isolation $(<-15 \mathrm{~dB})$. The proposed antenna resonated from 3.2 to $10.6 \mathrm{GHz}$, with an impedance bandwidth of 7.4 GHz. In [13], high isolation was achieved in a MIMO antenna with the help of an F-shaped stub. The dimensions of the design were $50 \mathrm{~mm} \times 30 \mathrm{~mm}$, and the range of the resonance frequency was $2.5-14.5 \mathrm{GHz}$, with an impedance bandwidth of $12 \mathrm{GHz}$, an isolation less than $-20 \mathrm{~dB}$, ECC less than 0.04, DG greater than $7.4 \mathrm{~dB}$, and multiplexing efficiency greater than $-3.5 \mathrm{~dB}$, respectively. In [14], a rectangular-shaped MIMO antenna with a T-shaped stub was studied to enhance isolation. The overall size of the antenna was $27 \mathrm{~mm} \times 47 \mathrm{~mm}$. The $\left|S_{11}\right|$ was less than $-10 \mathrm{~dB}$ in the entire UWB range, with an impedance bandwidth of $7.5 \mathrm{GHz}$. The isolation was less than $-17 \mathrm{~dB}$, and the maximum gain was $5.4 \mathrm{dBi}$, respectively.

A metamaterial, placed around a radiating element, can be used to improve the isolation. In [15], higher isolation was obtained with the help of a rectangular loop resonator type of metamaterial with an antenna size of $40 \mathrm{~mm} \times 80 \mathrm{~mm}$. The impedance bandwidth of the proposed design was $4.5-8 \mathrm{GHz}$, the isolation was less than $-25 \mathrm{~dB}$, ECC was less than 0.02 , and DG was nearly equal to $10 \mathrm{~dB}$. In [16], a proposed antenna was designed for a single band of $5.8 \mathrm{GHz}$, with overall dimensions of $37 \mathrm{~mm} \times 44 \mathrm{~mm}$. Technique using different kinds of stubs between the radiators is very helpful in obtaining significant isolation. In [17], a comb-line-shaped stub was used between U-shaped antennas to achieve a higher isolation. The dimensions of the antenna studied were $26 \mathrm{~mm} \times 31 \mathrm{~mm}$. The antenna $\left|S_{11}\right|$ had less than $-10 \mathrm{~dB}$ between 2.9 and $12 \mathrm{GHz}$, with an impedance bandwidth of $9.1 \mathrm{GHz}$. Another type of MIMO antenna with a T-shaped stub was used to improve isolation; the size of the studied antenna was $22 \mathrm{~mm} \times 31 \mathrm{~mm}$. The resonance frequency of the antenna was 2.9-12 GHz and the impedance bandwidth was $9.1 \mathrm{GHz}$ [18]. Similarly, mutual coupling was reduced through a defected ground structure (DGS) for a MIMO antenna operating in the frequency range of $5.77-5.96 \mathrm{GHz}$, with an impedance bandwidth of $190 \mathrm{MHz}$, isolation less than $-28 \mathrm{~dB}$, and ECC less than 0.003 [19].

In [20], a circular-shaped MIMO antenna was studied. A decoupling structure was introduced on both sides of the substrate. The size of the studied antenna was $4 \mathrm{~cm} \times 4 \mathrm{~cm}$; the impedance bandwidth was $7.9 \mathrm{GHz}$, operating from 3.1 to $11 \mathrm{GHz}$. In [21], a half-circular-shaped MIMO antenna is proposed with a resonance frequency of 3.1 to $12.3 \mathrm{GHz}$. The size of the antenna was $26 \mathrm{~mm} \times 55 \mathrm{~mm}$. In [22], mutual coupling was minimized with the help of a T-shaped stub, and the overall size of the antenna was $26 \mathrm{~mm} \times 28 \mathrm{~mm} \times 0.8 \mathrm{~mm}$. In [23], two decoupling structures printed on the back of a substrate were used to obtain isolation between antennas. The antenna had a rectangular shape with a MIMO structure that presented the overall dimensions of $25 \mathrm{~mm} \times 38 \mathrm{~mm}$, where $\left|S_{11}\right|$ was less than $-10 \mathrm{~dB}$, between 2.2 and $10.8 \mathrm{GHz}$. Additionally, a MIMO antenna with a circular shape was proposed for UWB applications in [24]. In that design, a single stub was used between the antennas to achieve high isolation. The overall size of the antenna was $35 \mathrm{~mm} \times 68 \mathrm{~mm}$ with a bandwidth of $7.55 \mathrm{GHz}$, operating from 3.1 to $10.65 \mathrm{GHz}$. Another type of T-shaped stub with a rectangular-shaped MIMO is 
proposed to reduce mutual coupling. The proposed antenna operated in the frequency range from 3.1 to $11 \mathrm{GHz}$, with a size of $22 \mathrm{~mm} \times 36 \mathrm{~mm}$, isolation less than $-15 \mathrm{~dB}$, ECC less than 0.1 , and where peak gain varied from 1 to $5 \mathrm{dBi}$ [25].

In [26], the authors designed an antenna with the overall dimensions of $30 \times 30 \times 0.8 \mathrm{~mm}^{3}$ and bandwidth of $7.9 \mathrm{GHz}$. It resonated from 3.08-10.98 GHz, and isolation was achieved with the help of a stepped-shaped ground stub. The DG was equal to $9.51 \mathrm{~dB}, \mathrm{ECC}$ was less than 0.013, and isolation was less or equal to $-20 \mathrm{~dB}$. In [27], the author proposed a rectangular-shaped fractal antenna with a T-shaped stub to reduce mutual coupling. The size of the antenna was $24 \times 32 \mathrm{~mm}^{2}$ and the impedance bandwidth as $9.4 \mathrm{GHz}$ from $3.1-12.5 \mathrm{GHz}$; the isolation wa less than $-16 \mathrm{~dB}$, DG was greater than $9.95 \mathrm{~dB}$, and ECC was less 0.05. In [28], the authors proposed a MIMO-UWB antenna with a circular ring resonator to be used for isolation. The size was $20 \times 34 \times 1.6 \mathrm{~mm}^{3}$ and bandwidth is $8 \mathrm{GHz}$, ranging from 3-11 GHz. In [29], the authors proposed a MIMO-UWB antenna with a size of $21 \times 34 \times 1.6 \mathrm{~mm}^{3}$. A neutralization line was used between radiating patches to achieve isolation. The antenna resonated from 3.62-9.35 GHz with a bandwidth of 5.73 GHz. In [30], the author proposed a MIMO-UWB antenna with a GSM band. The size of the unit cell is $36 \times 45 \times 1.6 \mathrm{~mm}^{3}$. The bandwidth of the proposed UWB antenna is $9.49 \mathrm{GHz}$, and for GSM, is $0.26 \mathrm{GHz}$, respectively. The isolation is less than $-20 \mathrm{~dB}$, peak gain varied between 4 and $8.48 \mathrm{dBi}$, and ECC was less than 0.025 .

In [31], authors proposed a semi-circular-shaped MIMO antenna, with overall dimensions of $40 \times 47 \mathrm{~mm}^{2}$, where the impedance bandwidth was $38.7 \mathrm{GHz}$, ranging from 1.3 to $40 \mathrm{GHz}$, and the isolation $(<-20 \mathrm{~dB})$ was increased through a T-shaped stub. The DG of the presented MIMO antenna was $10 \mathrm{~dB}, \mathrm{ECC}$ was less than 0.02 , and efficiency was greater than $80 \%$. In [32], authors presented coplanar waveguide (CPW)-fed SWB-MIMO antenna with a large size of $63 \times 63 \mathrm{~mm}^{2}$, and the impedance bandwidth achieved is $38.7 \mathrm{GHz}$, starting from 1.3 to $40 \mathrm{GHz}$. The peak gain of the presented antenna is $5.5 \mathrm{dBi}$, the isolation is less than $-16 \mathrm{~dB}$, and ECC is less than 0.01. In [33], a MIMO antenna as presented with a dimension of $45 \times 45 \mathrm{~mm}^{2}$, and $\left|S_{11}\right|$ was less than $-10 \mathrm{~dB}$ in an operating range of 2.2 to $13.5 \mathrm{GHz}$, with a total impedance bandwidth of $11.3 \mathrm{GHz}$. The gain of the proposed design was $6.8 \mathrm{dBi}$, isolation was less than $-18 \mathrm{~dB}$, and was less than 0.01 . The authors of [34] presented a UWB-MIMO antenna with a shared ground; the overall size of the antenna was $28.5 \times 28.5 \mathrm{~mm}^{2}$, and a high isolation was achieved with the help of an I-shaped stub between radiators. The total impedance bandwidth of the antenna was $8.42 \mathrm{GHz}$ between 2.66 and $11.08 \mathrm{GHz}$. The peak gain of the proposed MIMO antenna was $3.5 \mathrm{dBi}$, isolation was less than $-15 \mathrm{~dB}$, and ECC was less than 0.01. In [35], authors proposed a hexagonal-shaped MIMO antenna of a very large size $\left(28 \times 56 \mathrm{~mm}^{2}\right)$, isolation was achieved using parasitic elements and tree distinct-shaped stubs, and the impedance bandwidth was 11.3 GHz in a range of $2 \mathrm{GHz}$ to $13.3 \mathrm{GHz}$. The diversity gain was less than $9.985 \mathrm{dBi}$, ECC was less than 0.04 , peak gain was $6.6 \mathrm{dBi}$, and variable radiation efficiency was between $78 \%$ to $94 \%$.

In [36], a rectangular-shaped MIMO antenna was discussed, where a ground stub was introduced to reduce mutual coupling, and the size of the studied antenna was $26 \mathrm{~mm} \times 40 \mathrm{~mm}$. The impedance bandwidth was $7.5 \mathrm{GHz}$, operating from 3.1 to $10.6 \mathrm{GHz}$. The realized gain of the presented design was less than $4 \mathrm{dBi}$, ECC was less than 0.01, and isolation was less than -15 dB. In [37], a circular-fork-shaped MIMO antenna was proposed, with a resonance frequency range of 2.78 to $12.3 \mathrm{GHz}$, with a total bandwidth of $9.52 \mathrm{GHz}$, peak gain of $7 \mathrm{dBi}$, while maintaining a size of $35 \mathrm{~mm} \times 30 \mathrm{~mm}$. In [38], rectangular radiators were placed orthogonally to minimize mutual coupling, with an overall size of antenna of $23 \mathrm{~mm} \times 39.8 \mathrm{~mm}$, and operating frequency range of 2 to $12 \mathrm{GHz}$, with an impedance bandwidth of $10 \mathrm{GHz}$. The peak gain of the proposed design was $4 \mathrm{dBi}$, ECC was less than 0.01 , and isolation was less than $-20 \mathrm{~dB}$. In [39], radiators and decoupling structures were printed on both sides of a substrate in order to reduce mutual coupling and the size of the antennas. The rectangular shape of the antenna with a MIMO structure presented overall dimensions of $39 \mathrm{~mm} \times 39 \mathrm{~mm}$, and $\left|S_{11}\right|$ was less than $-10 \mathrm{~dB}$ between 2.02 and $10.7 \mathrm{GHz}$, with a total impedance bandwidth of $8.68 \mathrm{GHz}$. The peak gains and DG of the presented antenna were $4.6 \mathrm{dBi}$ and $9.5 \mathrm{~dB}$, respectively, ECC was less than 0.02 , isolation was less than $-22 \mathrm{~dB}$, and multiplexing efficiency was greater than $-3 \mathrm{~dB}$. Additionally, 
a dielectric resonator MIMO antenna with a frustum shape was proposed for SWB application by the authors of [40]. The overall size of the antenna was $95 \mathrm{~mm} \times 80 \mathrm{~mm}$ with a bandwidth of $27.6 \mathrm{GHz}$ operating from 7 to $34.6 \mathrm{GHz}$. The peak gain of the presented antenna was $9.5 \mathrm{dBi}$ at Port- 1 and $8 \mathrm{dBi}$ at Port-2; the DG was less than $9.99 \mathrm{~dB}, \mathrm{ECC}$ was less than 0.01 , and isolation was less than $-20 \mathrm{~dB}$.

In [41], a circular-shaped MIMO antenna was proposed with overall dimensions of $50 \times 30 \mathrm{~mm}^{2}$; the impedance bandwidth was $13 \mathrm{GHz}$ starting from 3 to $16 \mathrm{GHz}$, the ECC was less than 0.01, peak gain was $6 \mathrm{dBi}$, and isolation was less than $-16 \mathrm{~dB}$. In [42], a circular-shaped MIMO antenna with a size of $64 \times 45 \mathrm{~mm}^{2}$ was presented; the isolation was increased with a decoupling stub, and the impedance bandwidth was 8.5 , ranging from 2.5 to $11 \mathrm{GHz}$. The gain of the proposed antenna was $6 \mathrm{dBi}$, the ECC was less than 0.02 , and isolation was less than $-15 \mathrm{~dB}$. Various transmitters and receivers have also been designed for impulse radio UWB systems [43-45]. A detailed comparison between existing and proposed antennas are summarized in Table 1.

Table 1. Comparison between previously presented MIMO antennas with proposed antennas.

\begin{tabular}{|c|c|c|c|c|c|c|}
\hline Ref. & Year & Size $(\mathrm{mm} \times \mathbf{m m})$ & Resonance Freq: Range (GHz) & BW:1 & $\% \mathrm{BW}$ & BDR \\
\hline [1] & 2009 & $45 \times 37$ & $3.1-5$ & 1.61 & 47 & 264.36 \\
\hline [12] & 2011 & $40 \times 68$ & $3.2-10.6$ & 3.31 & 107.24 & 346.52 \\
\hline [13] & 2018 & $50 \times 30$ & $2.5-14.5$ & 5.8 & 141.17 & 1355.23 \\
\hline [14] & 2013 & $27 \times 47$ & $3.1-10.6$ & 3.41 & 109.50 & 808.11 \\
\hline [15] & 2019 & $40 \times 80$ & $4.5-8$ & 1.78 & 56 & 77.77 \\
\hline [17] & 2016 & $26 \times 31$ & 2.9-12 & 4.13 & 122.14 & 1621.69 \\
\hline [18] & 2018 & $22 \times 31$ & 2.9-12 & 4.13 & 122.14 & 1916.55 \\
\hline [20] & 2017 & $40 \times 40$ & $3.1-11$ & 3.54 & 112 & 655.56 \\
\hline [21] & 2015 & $26 \times 55$ & $3.1-12.3$ & 3.96 & 119.5 & 782.62 \\
\hline [22] & 2019 & $26 \times 28$ & 2.9-10.8 & 3.72 & 115.32 & 1695.19 \\
\hline [23] & 2018 & $25 \times 38$ & $2.2-10.8$ & 4.8 & 141 & 2759.89 \\
\hline [24] & 2016 & $35 \times 68$ & $3.1-10.65$ & 3.43 & 109.89 & 432.41 \\
\hline [25] & 2015 & $22 \times 36$ & $3.1-11$ & 3.54 & 112 & 1324.37 \\
\hline [26] & 2017 & $30 \times 30$ & $3.08-10.98$ & 3.56 & 112.37 & 1184.53 \\
\hline [27] & 2019 & $24 \times 32$ & $3.1-12.5$ & 4.03 & 120.51 & 1469.53 \\
\hline [28] & 2019 & $20 \times 34$ & $3.1-11$ & 3.54 & 112 & 1542.51 \\
\hline [29] & 2019 & $21 \times 34$ & $3.62-9.35$ & 2.58 & 88.35 & 849.83 \\
\hline [30] & 2019 & $36 \times 45$ & $3.01-12.5$ & 4.15 & 122.37 & 750.35 \\
\hline Proposed & 2020 & $18 \times 36$ & $3-40$ & 13.33 & 172.1 & 2655.86 \\
\hline
\end{tabular}

The proposed antenna is compared with those in the literature in terms of size, bandwidth, and bandwidth dimension ratio (BDR). The proposed antenna has a very small size and a large bandwidth in comparison with the literature cited. The term BDR is a measure of what percentage of a bandwidth is provided per unit area (i.e., bandwidth range and size compactness). The BDR of the proposed antenna is 2655.86, which is better than those mentioned in the literature cited in Table 1.

\section{Antenna Design and Characterization}

\subsection{Antenna Design}

The top and back views of the proposed antenna are depicted in Figure 1. The $|S|$ parameter results are depicted in Figure 2. The proposed antenna has: (i) two similar structures of a rectangular patch and a half-circular disc acting as radiating elements, (ii) a decoupling stub, and (iii) a ground plane. The overall dimensions of the proposed design are $18 \mathrm{~mm} \times 36 \mathrm{~mm}$. The proposed design is fabricated on FR4 substrate (thickness $=1.6 \mathrm{~mm}$, loss tangent $=0.02$ and relative permittivity $=4.4$ ). The radiating element consists of a rectangular patch and a half-circular disc. The radius of the half-circular disc is $4.4 \mathrm{~mm}$. Similarly, the length and width of the rectangular patch are 3.6 and $6 \mathrm{~mm}$, respectively. The rectangular patch is used to improve the lower cutoff frequency. The distance from one center of the radiating elements to another is $21.5 \mathrm{~mm}$. The length and the width of the feed line is 5.7 and $1.2 \mathrm{~mm}$, respectively. The width of the ground plane is the same as the antenna's overall width, and the length of the ground is $4.5 \mathrm{~mm}$. Various other design parameters are given in Table 2. 


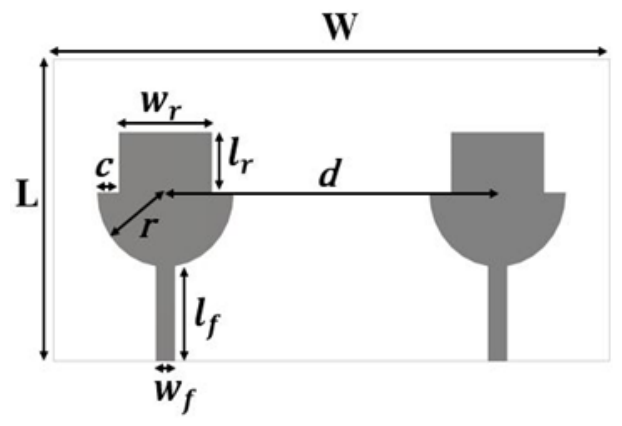

(a)

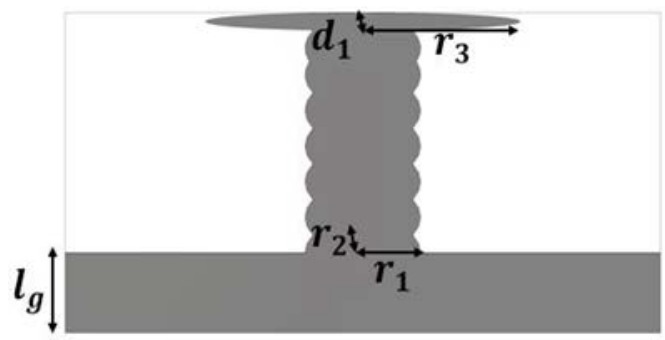

(b)

Figure 1. Design of MIMO antenna for SWB application. (a) Front view and (b) back view.

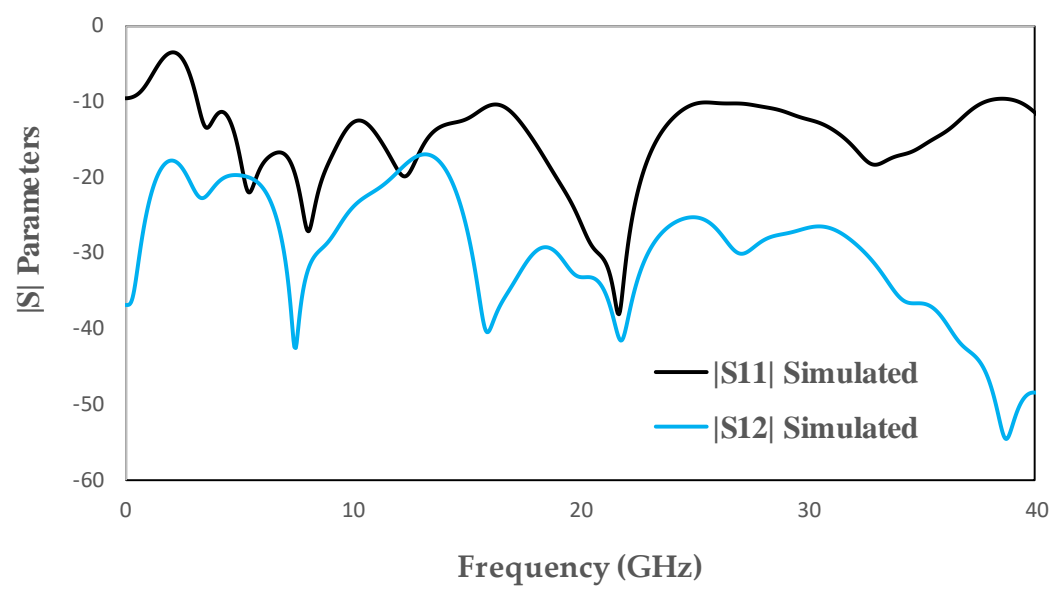

Figure 2. Simulated $|S|$ parameters of MIMO antenna for SWB applications.

Table 2. Parameters of proposed MIMO-UWB antenna.

\begin{tabular}{cccc}
\hline Parameter & Value $\mathbf{( m m )}$ & Parameter & Value $(\mathbf{m m})$ \\
\hline$W$ & 36 & $r$ & 4.4 \\
$L$ & 18 & $r_{1}$ & 3.5 \\
$l_{f}$ & 5.7 & $r_{2}$ & 2 \\
$l_{r}$ & 3.6 & $r_{3}$ & 9.5 \\
$l_{g}$ & 4.5 & $d$ & 21.5 \\
$w_{f}$ & 1.2 & $d_{1}$ & 1 \\
$w_{r}$ & 6 & $C$ & 1.4 \\
\hline
\end{tabular}

\subsection{Decoupling Stub}

Mutual coupling between the antenna elements is a major problem of MIMO antennas that affects the diversity performance of MIMO systems. Various types of decoupling stubs are used for isolation, such as Y-shaped, F- shaped and T-shaped [6-8]. Hence, reducing the mutual coupling through some isolation between antennas is the main challenge in MIMO systems [46]. In this design, a decoupling stub is used for high isolation between MIMO antennas. The geometry evaluation steps of the decoupling stub are depicted in Figure 3, and the reflection coefficient of the various steps is depicted in Figure 4. In Figure 3, MIMO Ant1 has a strong mutual coupling due to the absence of a decoupling stub. For MIMO Ant2, the I-shaped decoupling stub is introduced to improve isolation between antennas due to a change in the surface current distribution. However, some mutual coupling is still observed at some frequencies, which is obvious in Figure 4. Moreover, in MIMO Ant3, an elliptical strip is added to the top of the existing stub to reduce mutual coupling on the entire frequencies, shown in Figure 4. 


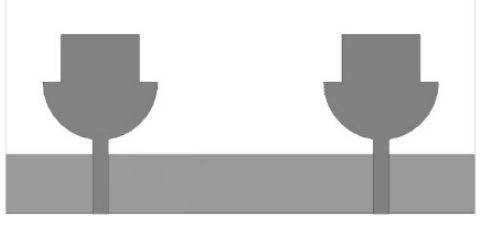

(a)

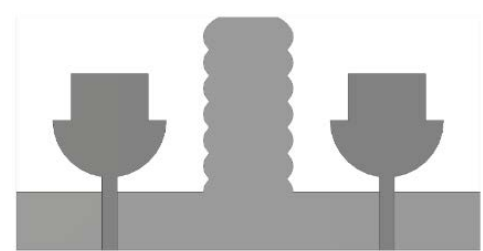

(b)

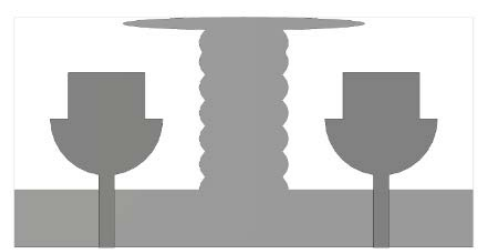

(c)

Figure 3. Design evaluation of decoupling stub in proposed MIMO antenna. (a) MIMO Ant1; (b) MIMO Ant2; and (c) MIMO Ant3.

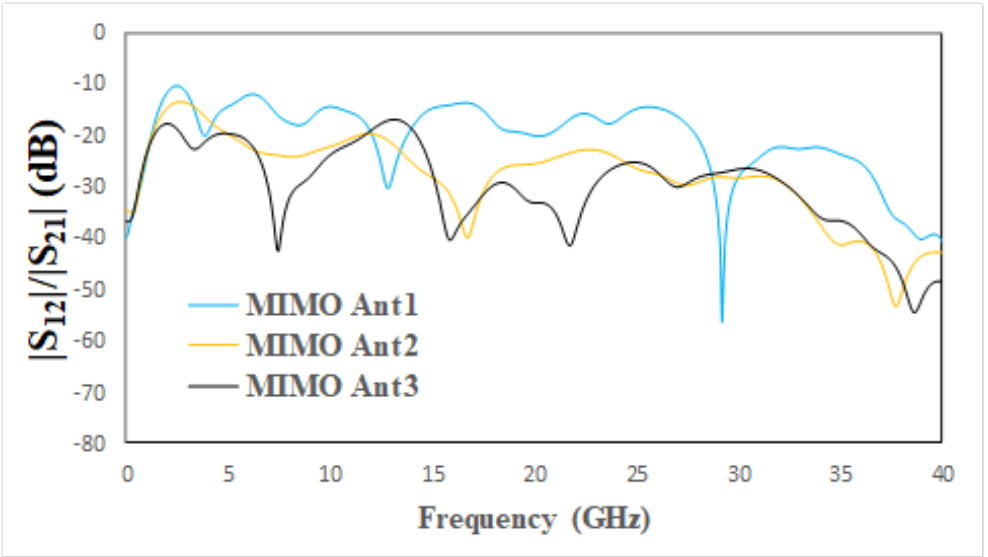

Figure 4. $|S|$ Parameters of design evaluation steps of decoupling stub.

In Figure 5, surface current distributions with and without decoupling stubs at various frequencies are also depicted. Surface current distribution is observed by exciting only port1. From Figure 5, without a decoupling stub, strong mutual coupling is observed. This is because of the coupling current proceeding from port1 to port2 in the MIMO antenna. By adding a decoupling stub, most of the current is concentrated on port1 towards the left side of the decoupling stub, which allows the interference rejection to result in high isolation on the other port.

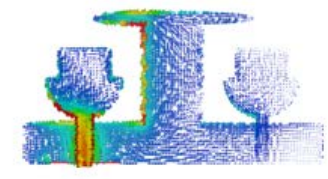

Port 1

(a) Port 2

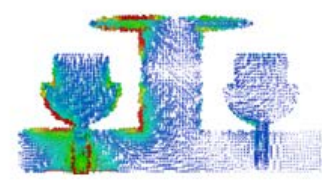

Port 1

(c) Port 2

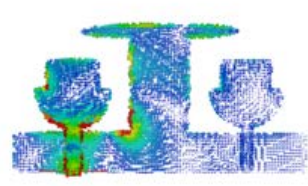

Port 1 (e) Port 2
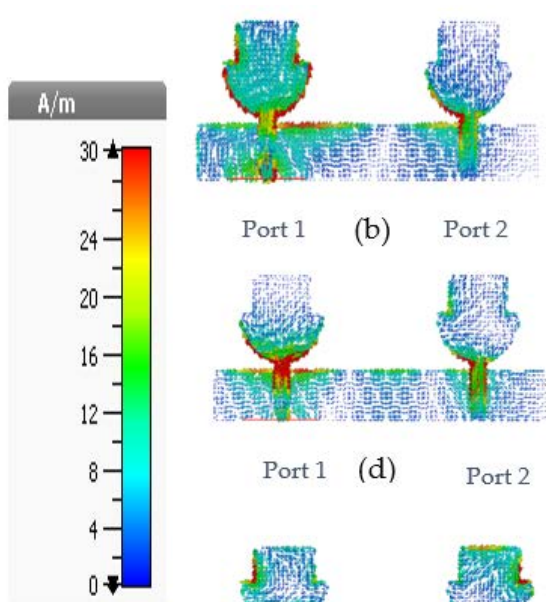

Port 1 (b) Port 2

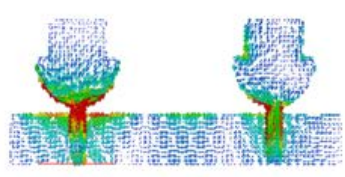

Port 1 (d) Port 2

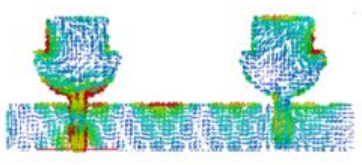

Port $1 \quad$ (f) Port 2

Figure 5. Surface current distribution of proposed MIMO antenna at (a) $5 \mathrm{GHz}$ with decoupling stub (b) $5 \mathrm{GHz}$ without decoupling stub (c) $10 \mathrm{GHz}$ with decoupling stub (d) $10 \mathrm{GHz}$ without decoupling stub (e) $15 \mathrm{GHz}$ with decoupling stub (f) $15 \mathrm{GHz}$ without decoupling stub. 


\section{Results and Discussion}

The proposed antenna design has two similar structures radiating elements: a decoupling stub and a ground plane. The proposed design is simulated and optimized in CST Microwave Studio (CST-MWS), an electromagnetic computer simulation program. The front and back view of fabricated MIMO antenna is depicted in Figure 6. The measured and simulated $|S|$ parameters are compared in Figure 7. It shows significant agreement between simulated and measured results. The antenna is radiating between 3 and $40 \mathrm{GHz}$. The simulated and measured radiation pattern at various frequencies in both E Plane ( $\mathrm{YZ}, \phi=90)$ and $\mathrm{H}$ Plane $(\mathrm{XZ}, \phi=0)$ are compared in Figure 8 . The radiation pattern at 3.5 GHz is nearly omni-directional in both the $Y Z$ Plane and $X Z$ Plane, the radiation patterns at 5.5 and $8 \mathrm{GHz}$ also form an omni directional pattern in the YZ Plane and XZ Plane. The radiation patterns are stable at the given frequencies, which is justified in Figure 8.

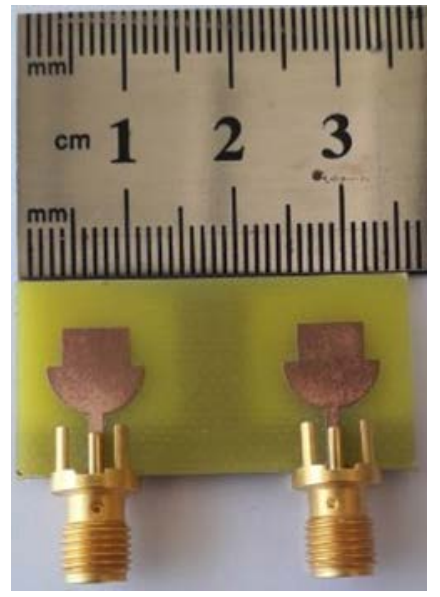

(a)

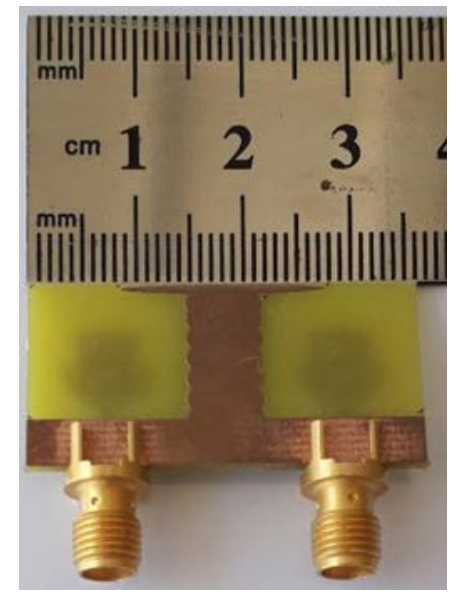

(b)

Figure 6. Fabricated design of proposed design. (a) Front view and (b) back view.

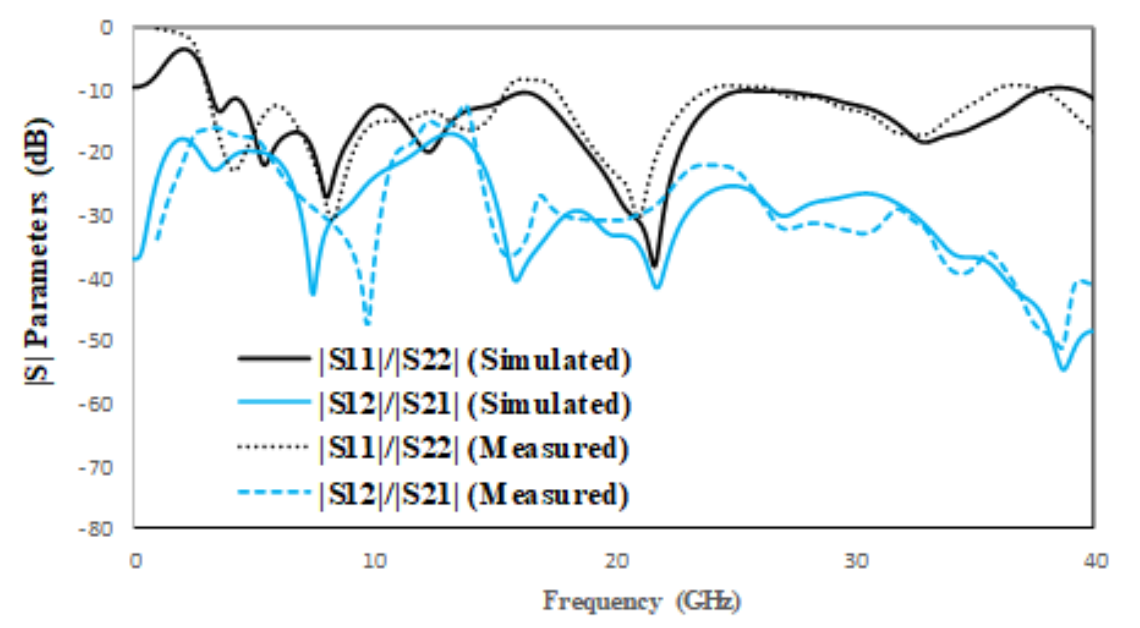

Figure 7. Measured and simulated $|S|$ parameters of proposed MIMO antenna. 


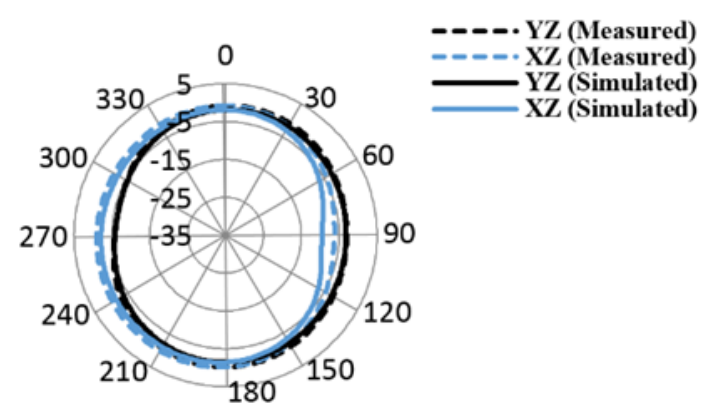

(b)

(a)
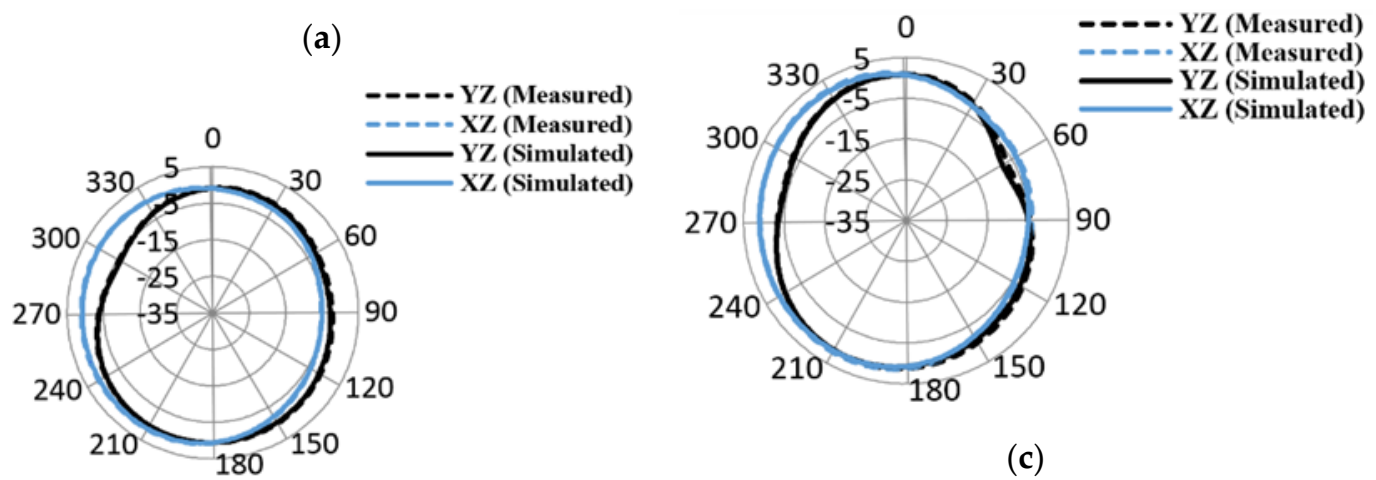

(c)

Figure 8. Measured and simulated radiation patterns (a) $3.3 \mathrm{GHz}$; (b) $5.5 \mathrm{GHz}$; and (c) $8 \mathrm{GHz}$.

Diversity gain (DG) and ECC are the most important performance parameters for the capability of a MIMO-UWB antenna. A value of ECC is ideally equal to zero, and, practically, ECC $<0.5$ for an uncorrelated MIMO antenna. ECC and DG are calculated from the following formula [47].

$$
\begin{gathered}
E C C=\frac{\left|S_{11}^{*} S_{12}+S_{21}^{*} S_{22}\right|^{2}}{\left(1-\left|S_{11}\right|^{2}-\left|S_{21}\right|^{2}\right)\left(1-\left|S_{22}\right|^{2}-\left|S_{12}\right|^{2}\right)} \\
D G=10 \sqrt{1-(E C C)^{2}}
\end{gathered}
$$

The measured and simulated ECC is $<0.01$ of the proposed antenna, which can be justified from Figure 9. The measured and simulated diversity gain is seen in Figure 9 that DG $>9.98 \mathrm{~dB}$. The peak gain and multiplexing efficiency are given in Figure 10, where measured and simulated peak gain varies between 0 and $4 \mathrm{dBi}$ over the entire frequencies. The multiplexing efficiency of the proposed design varies between -1 and $-3.5 \mathrm{~dB}$ over entire frequencies, which is justified from Figure 10 .

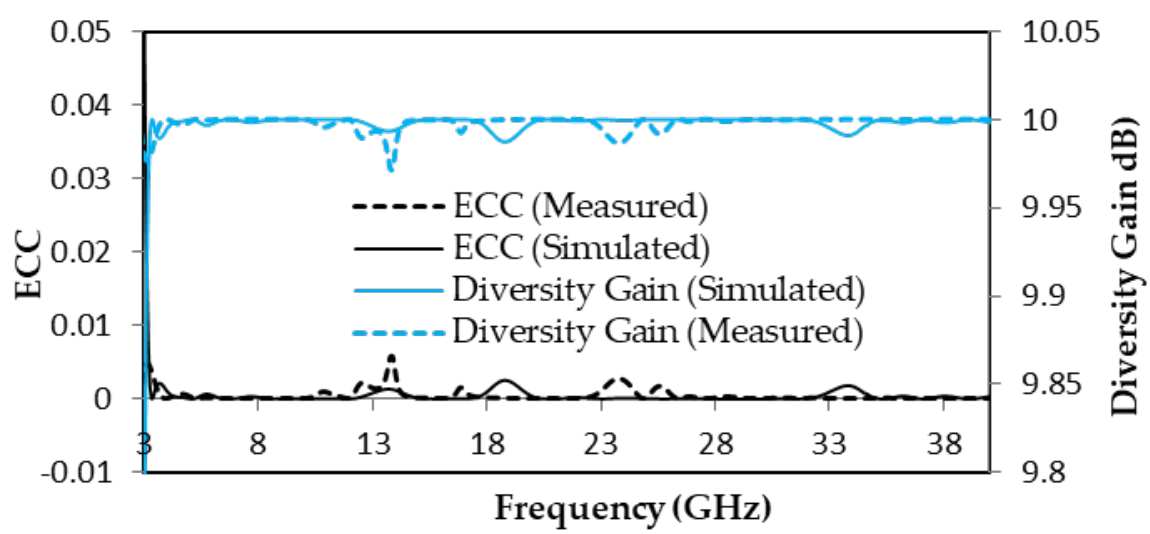

Figure 9. ECC and diversity gain of proposed antenna. 

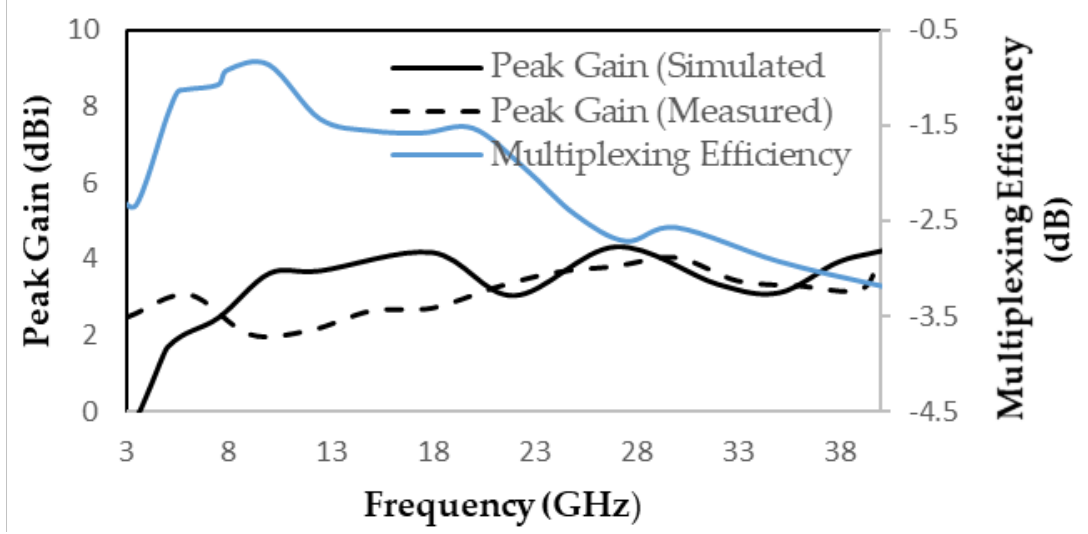

Figure 10. Multiplexing efficiency and peak gain of proposed MIMO antenna.

\section{Conclusions}

In this work, a new and more compact MIMO antenna with a novel-structured decoupling stub, enhanced bandwidth ( $37 \mathrm{GHz})$, and high isolation is presented. The size of the antenna is as small as $18 \mathrm{~mm} \times 36 \mathrm{~mm}$, while the isolation is increased by introducing a decoupling stub. The peak gain varies between 0 and $9 \mathrm{~dB}$ and achieved a comprehensive agreement between theoretical and measured results. The multiplexing efficiency, peak gain, ECC, and DG show that the proposed antenna can be used for various MIMO-UWB wireless applications.

Author Contributions: Original draft prepared by M.I.K. (Muhammad Irshad Khan), reviewed by S.U.R., A.B.Q., A.A.T., A.S. and supervised by M.I.K. (Muhammad Irfan Khattak). All authors have read and agreed to the published version of the manuscript.

Funding: This work was funded by the National Plan for Science Technology and Innovation (MAARIFAH) King Abul Aziz City for Science and Technology, Kingdom of Saudi Arabia Award Number (12-ELE2462-02).

Conflicts of Interest: The authors declare no conflict of interest.

\section{References}

1. See, T.S.P.; Chen, Z.N. An ultrawideband diversity antenna. IEEE Trans. Antennas Propag. 2009, 57, 1597-1605. [CrossRef]

2. Khan, M.I.; Khattak, M.I.; Witjaksono, G.; Barki, Z.U.; Ullah, S.; Khan, I.; Lee, B.M. Experimental Investigation of a Planar Antenna with Band Rejection Features for Ultra-Wide Band (UWB) Wireless Networks. Int. J. Antennas Propag. 2019, 2019, 11. [CrossRef]

3. Khattak, M.I.; Khan, M.I.; Ullah, Z.; Ahmad, G.; Khan, A. Hexagonal Printed Monopole Antenna with Triple Stop Bands for UWB Applications. Mehran Univ. Res. J. Eng. Technol. Pak. 2019, 38, 335-340. [CrossRef]

4. Zhang, X.; Ur Rahman, S.; Cao, Q.; Gil, I. A Novel SWB Antenna with Triple Band-Notches Based on Elliptical Slot and Rectangular Split Ring Resonators. Electron. J. 2019, 8, 1-17. [CrossRef]

5. Khan, M.I.; Rahman, S.; Khan, M.K.; Saleem, M. A Dual Notched Band Printed Monopole Antenna for Ultra Wide Band Applications. In Proceedings of the 2016 Progress in Electromagnetics Research (PIERS), Shanghai, China, 8-11 August 2016; pp. 4390-4393.

6. Khan, M.K.; Khan, M.I.; Ahmad, I.; Saleem, M. Design of a Printed Monopole Antenna with Ridged Ground for Ultra Wide Band Applications. In Proceedings of the 2016 Progress in Electromagnetics Research (PIERS), Shanghai, China, 8-11 August 2016; pp. 4394-4396.

7. Rahman, S.U.; Cao, Q.; Ullah, H.; Khalil, H. Compact design of trapezoid shape monopole antenna for SWB application. Microw. Opt. Technol. Lett. 2019, 61, 1931-1937. [CrossRef]

8. Li, M.; Luk, K.M. A differential-fed UWB antenna element with unidirectional radiation. IEEE Trans. Antennas Propag. 2016, 64, 3651-3656. [CrossRef]

9. Ren, J.; Hu, W.; Yin, Y.; Fan, R. Compact printed MIMO antenna for UWB applications. IEEE Antennas Wirel. Propag. Lett. 2014, 13, 1517-1520. 
10. Zheng, L.; Tse, D.N.C. Diversity and multiplexing: A fundamental tradeoff in multiple-antenna channels. IEEE Trans. Inf. Theory. 2003, 49, 1073-1096. [CrossRef]

11. Rajagopalan, A.; Gupta, G.; Konanur, A.S.; Hughes, B.; Lazzi, G. Increasing channel capacity of an ultrawideband MIMO system using vector antennas. IEEE Trans. Antennas Propag. 2007, 55, 2880-2887. [CrossRef]

12. Najam, A.I.; Duroc, Y.; Tedjni, S. UWB-MIMO antenna with novel stub structure. Prog. Electromagn. Res. 2011, 19, 245-257. [CrossRef]

13. Iqbal, A.; Saraereh, O.A.; Ahmad, A.W.; Bashir, S. Mutual coupling reduction using F-shaped stubs in UWB-MIMO antenna. IEEE Access. 2018, 6, 2755-2759. [CrossRef]

14. Khan, M.S.; Shafique, M.F.; Capobianco, A.D.; Autizi, E.; Shoaib, I. Compact UWB-MIMO antenna array with a novel decoupling structure. In Proceedings of the 2013 10th International Bhurban Conference on Applied Sciences \& Technology (IBCAST), Islamabad, Pakistan, 15-19 January 2013; pp. 347-350.

15. Jabire, A.; Zheng, H.X.; Abdu, A.; Song, Z. Characteristic mode analysis and design of wide band MIMO antenna consisting of metamaterial unit cell. Electronics 2019, 8, 68. [CrossRef]

16. Iqbal, A.; A Saraereh, O.; Bouazizi, A.; Basir, A. Metamaterial-based highly isolated MIMO antenna for portable wireless applications. Electronics 2018, 7, 267. [CrossRef]

17. Malekpour, N.; Honarvar, M.A. Design of high-isolation compact MIMO antenna for UWB application. Prog. Electromagn. Res. C 2016, 62, 119-129. [CrossRef]

18. Li, W.; Hei, Y.; Grubb, P.M.; Shi, X.; Chen, R.T. Compact inkjet-printed flexible MIMO antenna for UWB applications. IEEE Access 2018, 6, 50290-50298. [CrossRef]

19. Ibrahim, A.A.; Abdalla, M.A.; Abdel-Rahman, A.B.; Hamed, H.F. Compact MIMO antenna with optimized mutual coupling reduction using DGS. Int. J. Microw. Wirel. Technol. 2014, 6, 173-180. [CrossRef]

20. Ali, W.A.; Ibrahim, A.A. A compact double-sided MIMO antenna with an improved isolation for UWB applications. Aeu-Int. J. Electron. Commun. 2017, 82, 7-13. [CrossRef]

21. Toktas, A.; Akdagli, A. Compact multiple-input multiple-output antenna with low correlation for ultra-wide-band applications. Iet Microw. Antennas Propag. 2015, 9, 822-829. [CrossRef]

22. Zhao, Y.; Zhang, F.S.; Cao, L.X.; Li, D.H. A Compact Dual Band-Notched MIMO Diversity Antenna for UWB Wireless Applications. Prog. Electromagn. Res. 2019, 89, 161-169. [CrossRef]

23. Azarm, B.; Nourinia, J.; Ghobadi, C.; Majidzadeh, M.; Hatami, N. A Compact WiMAX Band-Notched UWB MIMO Antenna with High Isolation. Radioengineering 2018, 27, 983-989. [CrossRef]

24. Li, W.T.; Hei, Y.Q.; Subbaraman, H.; Shi, X.W.; Chen, R.T. Novel printed filtenna with dual notches and good out-of-band characteristics for UWB-MIMO applications. IEEE Microw. Wirel. Compon. Lett. 2016, 26, 765-767. [CrossRef]

25. Liu, L.; Cheung, S.W.; Yuk, T.I. Compact MIMO antenna for portable UWB applications with band-notched characteristic. IEEE Trans. Antennas Propag. 2015, 63, 1917-1924. [CrossRef]

26. Biswal, S.P.; Das, S. A low profile dual port UWB-MIMO/diversity antenna with band rejection ability. Int J. RF Microw Comput Aided Eng. 2017, 28, e21159. [CrossRef]

27. Gurjar, R.; Upadhyay, D.K.; Kanaujia, B.K.; Sharma, K. A novel compact self-similar fractal UWB MIMO antenna. Int. J. Rf Microw. Comput. Aided Eng. 2019, 29, e21632. [CrossRef]

28. Mathur, R.; Dwari, S. A compact UWB-MIMO with dual grounded CRR for isolation improvement. Int. J. Rf Microw. Comput. Aided Eng. 2019, 29, e21500. [CrossRef]

29. Tiwari, R.N.; Singh, P.; Kanaujia, B.K. A compact UWB MIMO antenna with neutralization line for WLAN/ISM/mobile applications. Int. J. Rf Microw. Comput. Aided Eng. 2019, 29, e21907. [CrossRef]

30. Srivastava, K.; Kumar, A.; Kanaujia, B.K.; Dwari, S.; Kumar, S. A CPW-fed UWB MIMO antenna with integrated GSM band and dual band notches. Int. J. Rf Microw. Comput. Aided Eng. 2019, 29, e21433. [CrossRef]

31. Ullah, H.; Rahman, S.U.; Cao, Q.; Khan, I.; Ullah, H. Design of SWB MIMO Antenna with Extremely Wideband Isolation. Electronics 2020, 9, 194. [CrossRef]

32. Kumar, P.; Urooj, S.; Alrowais, F. Design of quad-port MIMO/Diversity antenna with triple-band elimination characteristics for super-wideband applications. Sensors 2020, 20, 624. [CrossRef]

33. Kumar, P.; Urooj, S.; Malibari, A. Design of Quad-Port Ultra-Wideband Multiple-Input-Multiple-Output Antenna with Wide Axial-Ratio Bandwidth. Sensors 2020, 20, 1174. [CrossRef]

34. Liu, Y.F.; Wang, P.; Qin, H. Compact ACS-fed UWB antenna for diversity applications. Electron. Lett. 2014, 50, 1336-1338. [CrossRef] 
35. Addepalli, T.; Anitha, V.R. Design and Parametric Analysis of Hexagonal Shaped MIMO Patch Antenna for S-Band, WLAN, UWB and X-Band Applications. Prog. Electromagn. Res. 2019, 97, 227-240. [CrossRef]

36. Liu, L.; Cheung, S.W.; Yuk, T.I. Compact MIMO antenna for portable devices in UWB applications. IEEE Trans. Antennas Propag. 2013, 61, 4257-4264. [CrossRef]

37. Tu, Z.H.; Li, W.A.; Chu, Q.X. Single-layer differential CPW-fed notch-band tapered-slot UWB antenna. IEEE Antennas Wirel. Propag. Lett. 2014, 13, 1296-1299.

38. Khan, M.S.; Capobianco, A.D.; Naqvi, A.; Shafique, M.F.; Ijaz, B.; Braaten, B.D. Compact planar UWB MIMO antenna with on-demand WLAN rejection. Electron. Lett. 2015, 51, 963-964.

39. Tang, Z.; Wu, X.; Zhan, J.; Hu, S.; Xi, Z.; Liu, Y. Compact UWB-MIMO antenna with high isolation and triple band-notched characteristics. IEEE Access 2019, 7, 19856-19865. [CrossRef]

40. Gotra, S.; Varshney, G.; Pandey, V.S.; Yaduvanshi, R.S. Super-wideband multi-input-multi-output dielectric resonator antenna. Iet Microw. Antennas Propag. 2019, 14, 21-27. [CrossRef]

41. Kumar, A.; Ansari, A.Q.; Kanaujia, B.K.; Kishor, J.; Tewari, N. Design of triple-band MIMO antenna with one band-notched characteristic. Prog. Electromagn. Res. 2018, 86, 41-53. [CrossRef]

42. Jaglan, N.; Gupta, S.D.; Thakur, E.; Kumar, D.; Kanaujia, B.K.; Srivastava, S. Triple band notched mushroom and uniplanar EBG structures based UWB MIMO/Diversity antenna with enhanced wide band isolation. Aeu Int. J. Electron. Commun. 2018, 90, 36-44. [CrossRef]

43. Tatsis, G.; Votis, C.; Raptis, V.; Christofilakis, V.; Chronopoulos, S.K.; Kostarakis, P. Design and Implementation of Ultra-Wideband Impulse Radio Transmitter. In AIP Conference Proceedings; American Institute of Physics: Thessaloniki, Greece, 2010; Volume 1203, pp. 579-584.

44. Angelis, C.T.; Chronopoulos, S.K. System performance of an LTE MIMO downlink in various fading environments. In International Conference on Ambient Media and Systems; Springer: Berlin/Heidelberg, Germany, 2011; pp. 36-43.

45. Tatsis, G.; Votis, C.; Raptis, V.; Christofilakis, V.; Chronopoulos, S.K.; Kostarakis, P. Performance of UWB-Impulse Radio Receiver Based on Matched Filter Implementation with Imperfect Channel Estimation. In AIP Conference Proceedings; American Institute of Physics: Thessaloniki, Greece, 2010; Volume 1203, pp. 573-578.

46. Zheng, J.; Li, Y.; Feng, Z. Impact of mutual coupling and polarization of antennas on BER performances of spatial multiplexing MIMO systems. Int. J. Antennas Propag. 2012, 2012, 12. [CrossRef]

47. Blanch, S.; Romeu, J.; Corbella, I. Exact representation of antenna system diversity performance from input parameter description. Electron. Lett. 2003, 39, 705-707. [CrossRef]

(C) 2020 by the authors. Licensee MDPI, Basel, Switzerland. This article is an open access article distributed under the terms and conditions of the Creative Commons Attribution (CC BY) license (http://creativecommons.org/licenses/by/4.0/). 